\title{
INTERPRETATION OF DIFFERENTIAL ANOMALOUS X-RAY SCATTERING DATA FOR AMORPHOUS Cd-As
}

\author{
A. BURIAN \\ Department of Solid State Pliysics, Polish Academy of Sciences \\ Waudy 3, 41-800 Zabrze, Poland \\ P. Lecante, A. Mosset, J. Galy \\ CEMES-LOE/CNRS, 29 rue J. Marvig, BP 4347, 31055 Toulouse Cedex, France \\ J.M. TONNERRE aNd D. RaOUX \\ Laboratoire de Cristallographie, UPR CNRS 503 \\ BP 166X, 38042 Grenoble Cedex, France \\ The computational procedure, based on Warren's exact method for \\ an amorphous sample with more than one atom, was developed to obtain \\ the short-range order structural parameters from the differential anomalous \\ $\mathrm{X}$-ray scattering data, collected using the synchrotron radiation. The ex- \\ perimental differential radial distribution functions were fitted with the true \\ distribution functions expressed in an analytical form and broadened by con- \\ volution with the pair functions. It was found that atoms in the amorphous \\ Cd-As films remain almost tetrahedrally coordinated and the investigated \\ alloys are chemically ordered.
}

PACS numbers: 61.10.-i, 78.70.Dm

\section{Introduction}

Two-component amorphous semiconductors have become of interest recently because of their possibility for applications and their contribution to the understanding of the transport and optical properties of noncrystalline systems. The majority of reports in the literature on these materials refers to III- $V$ amorphous films Ga-As, Ga-P and In-P [1-7]. The basic factor which determines the electrical and optical characteristics, i.e. the electronic valence and conduction band densities of states and the size of the band gap, is the structural disorder, either 
configurational or chemical. The chemical disorder relates to a bonding arrangement in which the minority component is coordinated not only by atoms of the majority kind. The configurational disorder refers to fluctuations in both bond lengths and angles.

The structural information about short-range ordering in amorphous materials is usually derived from the large-angle X-ray scattering (LAXS) and extended X-ray absorption fine structure (EXAFS) experiments. Recently, the synchrotron radiation technique of differential anomalous X-ray scattering (DAXS) has proved to be a very effective tool for the structural studies of two-component noncrystalline semiconductors as amorphous $\mathrm{Ga}-\mathrm{As}[3,4]$ and glassy $\mathrm{As}-\mathrm{Te}[8]$. This technique yields the structural information which is qualitatively similar to that obtained from EXAFS but includes long-range correlations [9]. In this paper the exact interpretation method of the DAXS data in the short-range region is described. The results of the studies performed on the vacuum evaporated amorphous $\mathrm{Cd}_{59} \mathrm{As}_{41}$ and $\mathrm{Cd}_{26} \mathrm{As}_{74}$ films are compared with those previously obtained using the approximate method.

\section{Theoretical outline}

For two-component material the DAXS teclinique uses four complete sets of scattering data taken at four different photon energies near the absorption edge of both constituents, two for each edge, denoted here as " $\alpha$ ". The differences of the intensities $\Delta I^{\alpha}(\alpha=A \mathrm{~s}$ or $\mathrm{Cd})$ scattered at two energies immediately and further below the absorption edges of both components yield the differential structure factor $\Delta S^{\alpha}$

$$
\Delta S^{\alpha}(K)=\frac{\Delta I^{\alpha}(K)-\Delta^{\alpha}\left[\left\langle f^{2}\right\rangle-\langle\zeta\rangle^{2}\right]}{\Delta^{\alpha}\left[\langle f\rangle^{2}\right]}
$$

where $K=4 \pi \sin \theta / \lambda$ is the magnitude of the scattering vector, $\Delta^{\alpha}[]$ indicates the difference between two energies of the quantity in square brackets, taken at energies near the $K$-edge of $\alpha$-th atom, and $\langle f\rangle=\sum_{i=1}^{2} c_{i}\left|f_{i}\right|,\left\langle f^{2}\right\rangle=\sum_{i=1}^{2} c_{i}\left|f_{i}\right|^{2}$, $c_{i}$ denotes the atomic concentration of species $i, f$ is the atomic scattering factor. The differential structure factor (DSF) for a binary material is defined as the weighted sum

$$
\Delta S^{\alpha}(K)=\sum_{i=1}^{2} \sum_{j=1}^{2} \Delta W_{i j}^{\alpha} S_{i j}(K)
$$

of the partial structure factor $S_{i j}$, where

$$
\Delta W_{i j}^{\alpha}(K)=\frac{c_{i} c_{j} \Delta^{\alpha}\left[f_{i} f_{j}\right]}{\Delta^{a}\left[\langle f\rangle^{2}\right]} .
$$

The differential radial distribution function (DRDF) $4 \pi r^{2} \Delta \rho^{\alpha}(r)$ is calculated as the Fourier sine transform

$$
4 \pi r^{2} \Delta \rho^{\alpha}(r)=4 \pi r^{2} \rho_{0}+\frac{2 r}{\pi} \int_{0}^{K_{\max }} K\left[\Delta S^{\alpha}(K)-1\right] \exp \left(-\beta K^{2}\right) \sin (K r) \mathrm{d} K,(4)
$$

$\beta=0.02$ and 0.0075 for data at the $\Lambda$ s and Cd $K$-edge, respectively. 
For two data sets, the anomalous scattering factor varies markedly for the atomic species $\alpha$ at the energy very close to the edge, whereas the changes in the other scattering factor are small. Thus DSF or DRDF are sensitive only to the partial components involving species $\alpha$.

Assuming three-dimensional Gaussian distribution of interatomic distances, the DRDF function can be calculated averaging this distribution over all orientations as given in Refs. [10-12]. Now DRDF may be written as

$$
\begin{array}{r}
4 \pi r^{2} \Delta \rho^{\alpha}(r)=r \sum_{i=1}^{2} \sum_{j=1}^{2} c_{i} \sum_{k} \int_{0}^{\infty} \frac{N_{i j}^{k}}{r_{i j}^{k}}\left\{\exp \left[\frac{\left(r^{\prime}-r_{i j}^{k}\right)^{2}}{2\left(\sigma_{i j}^{k}\right)^{2}}\right]\right. \\
\left.-\exp \left[\frac{\left(r^{\prime}+r_{i j}^{k}\right)^{2}}{2\left(\sigma_{i j}^{k}\right)^{2}}\right]\right\}\left[\Delta P_{i j}^{\alpha}\left(r-r^{\prime}\right)-\Delta P_{i j}^{\alpha}\left(r+r^{\prime}\right)\right] \mathrm{d} r^{\prime} .
\end{array}
$$

The pair functions $\Delta P_{i j}^{\alpha}$ are defined by the following expression:

$$
\Delta P_{i j}^{\alpha}(r)=\frac{1}{\pi} \int_{0}^{K_{\max }} \frac{\Delta W_{i j}^{\alpha}(K)}{c_{i} c_{j}} \exp \left(-\beta K^{2}\right) \cos (K r) \mathrm{d} K .
$$

In Eq. (5) the third sum is taken over all coordination spheres, $N_{i j}^{k}$ indicates the number of $j$-th kind atoms around $i$-th atom in $k$-th coordination sphere at the distance $r_{i j}^{k}$, a value $\sigma_{i j}^{k}$ is the standard deviation of $r_{i j}^{k}$. Equation (5) is the base of the exact interpretation of the DAXS data, analogous to Warren's interpretation method proposed for classical LAXS [13]. Using this equation the structural parameters as coordination numbers, interatomic distances and their standard deviations can be obtained by fitting procedure. Sucl an approach allows one to take into account the $K$ dependence of the weighting factors and broadening of the DRDF peaks resulting from truncation of the experimental data at $K_{\max }$.

\section{Results and discussion}

The X-ray scattering data were collected on the DCI positron ring at LURE (Orsay, France). The experiments and the data trealment have been described in detail in our previous paper [14]. The weighting factors $\Delta W_{i j}^{\alpha}$ for both compositions are shown in Figs. 1 and 2 together with the computed $\Delta P_{i j}^{\alpha}$ functions.

From inspection of the presented plots it can be seen that $\Delta W_{\mathrm{Cd}-\mathrm{Cd}}^{\mathrm{As}}$, $\Delta W_{\mathrm{As}-\mathrm{As}}^{\mathrm{Cd}}$ and relevant $\Delta P_{\mathrm{Cd}-\mathrm{Cd}}^{\mathrm{As}}, \Delta P_{\mathrm{As}-\mathrm{As}}^{\mathrm{Cd}}$ are reduced practically to zero. For the remaining atomic pairs the weighting factors are clearly $K$ dependent. Therefore the precise interpretation of the DRDF function requires the use of the technique described in the previous section. The curve-fitting method which utilises the IIook-Jeeves type procedure was used [15]. During fitting the values of the interatomic distances, the coordination numbers and the standard deviations of the distances were allowed to vary. The sum of the residuals between the model calculations based on Eq. (4) and the experimental function divided by the number of the independent data points were criteria of goodness of the fit.

The experimental and calculated curves are compared in Figs. 3 and 4 , the resulting structural parameters are collected in Table. The values of the coordination numbers and the interatomic distances, presented in this paper, do not 

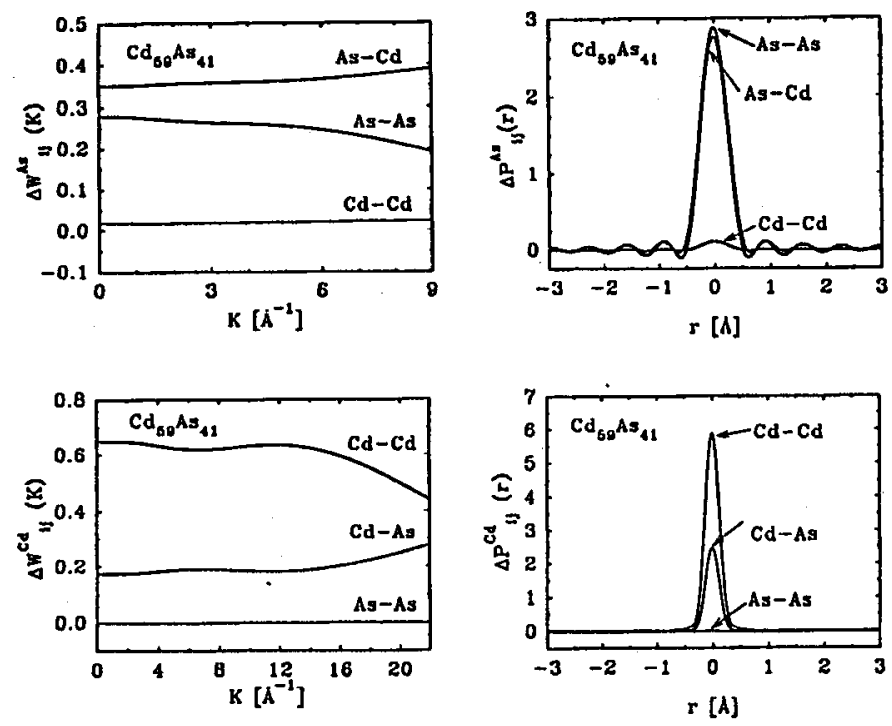

Fig. 1. The differential weighting factors and the relevant differential pair functions for $\mathrm{Cd}_{59} \mathrm{As}_{41}$ at the $\mathrm{As}$ and $\mathrm{Cd} K$-cdges.
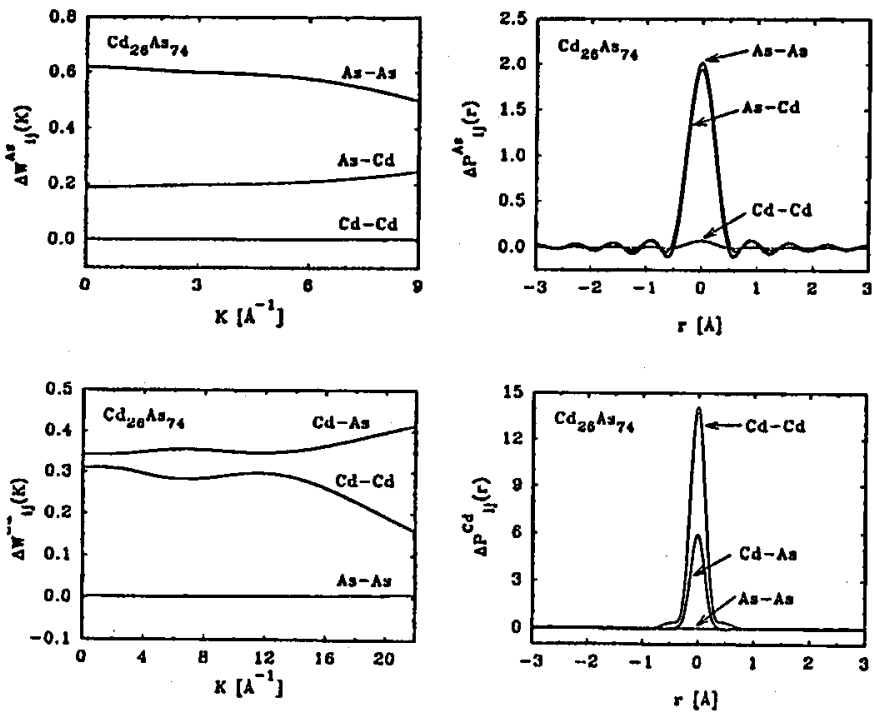

Fig. 2. The differential weighting factors and the relevant differential pair functions for $\mathrm{Cd}_{26} \mathrm{As}_{74}$ at the As and $\mathrm{Cd} K$-edges.

differ substantially from those derived from the peak areas and positions using the simplified method which neglects the $K$ dependence of the weighting factors [14]. The proposed procedure is not only more correct from the methodological point of view. The curve-fitting method allows one to evaluate the structural parameters more precisely and additionally offers new possibility as an estimation of the 

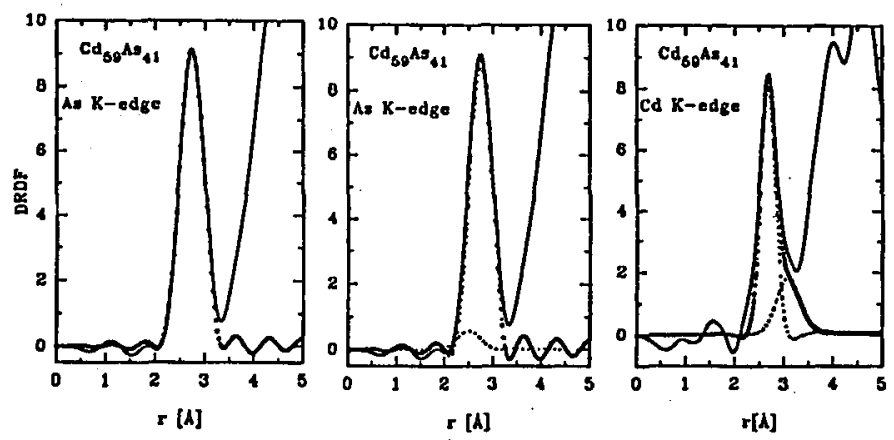

Fig. 3. The experimental (solid line) and simulated (filled circles) DRDF functions for $\mathrm{Cd}_{59} \mathrm{As}_{41}$; the one- and two-shell fits at the As $K$-edge and the two-shell fit at the Cd $K$-edge together with the partial contributions (dotted line).
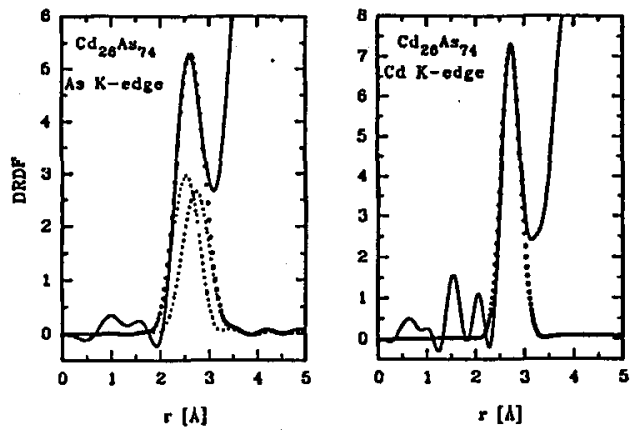

Fig. 4. The experimental (solid line) and simulated (filled circles) DRDF functions for $\mathrm{Cd}_{26} \mathrm{As}_{74}$; the two-shell fit at the As $K$-cdge and the one-shell fit at the Cd $K$-edge together with the partial contributions (dotted line).

spread of the bond lengths. It is noteworthy that the unambiguous estimation of the peak area may be complicated when the peak is not well separated from the next coordination contribution.

Several models have been tested to simulate the first coordination sphere around $\mathrm{As}$ and $\mathrm{Cd}$ in the investigated films. For the $\mathrm{Cd}$-rich film the one-shell model accounts very well for the experimental data. However, the small As-As contribution, on the average $0.5 \mathrm{As}$ atoms, cannot be completely ruled out within the method precision (see Fig. 3). The coordination number greater than 0.5 leads to poorer agreement with the experimental curve. Comparison of these coordination numbers with the results previously obtained basing on the paracrystalline model with the $1: 1$ stoichiometry in which each $\mathrm{Cd}$ is coordinated by $1 \mathrm{Cd}$ and $3 \mathrm{As}$ and each $\mathrm{As}$ has $1 \mathrm{As}$ and $3 \mathrm{Cd}$ as the near neighbours, suggests that in the one-shell model the As positions around the arsenic atoms are substituted by $\mathrm{Cd}$. The coordination numbers obtained from the two-shell fitting can be explained by the statistical occupation of $\mathrm{As}$ by $\mathrm{As}$ and $\mathrm{Cd}$, in the proportion depending on the 
TABLE

The interatomic distances $[\AA]$, the coordination numbers and the spread of the bond lengths $[\AA]$ obtained from the curve-fitting method for the first coordination sphere of amorphous $\mathrm{Cd}_{59} \mathrm{As}_{41}$ and $\mathrm{Cd}_{26} \mathrm{As}_{74}$. The estimated errors are given in brackets $( \pm)$.

\begin{tabular}{|c|c|c|}
\hline \multirow[t]{2}{*}{ Sample } & \multicolumn{2}{|c|}{$K$-edge } \\
\hline & As & $\mathrm{Cd}$ \\
\hline $\mathrm{Cd}_{59} \mathrm{As}_{41}$ & $\begin{array}{c}1 \text { shell } \\
r_{\mathrm{As}-\mathrm{Cd}}=2.68(0.02) \\
N_{\mathrm{As}-\mathrm{Cd}}=4.40(0.25) \\
\sigma_{\mathrm{As}-\mathrm{Cd}}=0.12(0.02) \\
2 \text { shells } \\
r_{\mathrm{As}-\mathrm{As}}=2.45(0.03) \\
N_{\mathrm{As}-\mathrm{As}}=0.50(0.50) \\
\sigma_{\mathrm{As}-\mathrm{As}}=0.06(0.02) \\
r_{\mathrm{As}-\mathrm{Cd}}=2.70(0.03) \\
N_{\mathrm{As}-\mathrm{Cd}}=3.90(0.50) \\
\sigma_{\mathrm{As}-\mathrm{Cd}}=0.06(0.02)\end{array}$ & $\begin{array}{l}r_{\mathrm{Cd}-\mathrm{Cd}}=3.05(0.03) \\
N_{\mathrm{Cd}-\mathrm{Cd}}=1.00(0.50) \\
\sigma_{\mathrm{Cd}-\mathrm{Cd}}=0.20(0.05) \\
r_{\mathrm{Cd}-\mathrm{As}}=2.67(0.03) \\
N_{\mathrm{Cd}-\mathrm{As}}=3.30(0.50) \\
\sigma_{\mathrm{Cd}-\mathrm{As}}=0.08(0.02)\end{array}$ \\
\hline $\mathrm{Cd}_{26} \mathrm{As}_{74}$ & $\begin{array}{c}1 \text { shell } \\
2 \text { shells } \\
r_{\mathrm{As}-\mathrm{As}}=2.47(0.03) \\
N_{\mathrm{As}-\mathrm{As}}=2.30(0.50) \\
\sigma_{\mathrm{As}-\mathrm{As}}=0.15(0.02) \\
r_{\mathrm{As}-\mathrm{Cd}}=2.67(0.03) \\
N_{\mathrm{As}-\mathrm{Cd}}=1.20(0.50) \\
\sigma_{\mathrm{As}-\mathrm{Cd}}=0.19(0.02)\end{array}$ & $\begin{array}{l}r_{\mathrm{Cd}-\mathrm{As}}=2.70(0.03) \\
N_{\mathrm{Cd}-\mathrm{As}}=3.70(0.50) \\
\sigma_{\mathrm{Cd}-\mathrm{As}}=0.15(0.02)\end{array}$ \\
\hline
\end{tabular}

chemical composition. The contribution at about $3 \AA$ in DRDF calculated near the Cd-edge and its absence in As-edge DRDF is interpreted as resulting from the $\mathrm{Cd}-\mathrm{Cd}$ bonds because only the partial $\mathrm{Cd}-\mathrm{Cd}$ component is involved in $\mathrm{Cd}-\mathrm{DRDF}$ and not in As-DRDF. Attempts made to fit the experimental Cd-DRDF function by the model consisting of the $\mathrm{Cd}-\mathrm{As}$ contribution at about $2.7 \AA$ and the next neighbour contribution at about $4 \AA$ proved ineflective. Ilowever, the fit in this region can be improved if one takes into account the next neighbour correlation together with the $\mathrm{Cd}-\mathrm{Cd}$ peak at $3.05 \AA$. On the other hand the one-shell fit leads to 
the value of $N_{\mathrm{Cd}-\mathrm{As}}=4.6$ which is clearly incompatible with the bond-consistency condition

$$
c_{\mathrm{Cd}} N_{\mathrm{Cd}-\mathrm{As}}=c_{\mathrm{As}} N_{\mathrm{As}-\mathrm{Cd}} .
$$

The presented model describes only the short-range order correlations and is far from being complete. The description of the atomic arrangement in the large scale of the interatomic distances will be the subject of our subsequent paper. For $\mathrm{Cd}_{26} \mathrm{As}_{74}$ the one-shell fit performed at Cd edge DRDF, based on the assumption that only $\mathrm{As}$ is the near neighbour to $\mathrm{Cd}$, gives the coordination number $N_{\mathrm{Cd}-\mathrm{As}}$ equal to 3.7. At the As edge the model composed of two subshells As-As and As-Cd with $N_{\mathrm{As}-\mathrm{As}}=2.3$ and $N_{\mathrm{As}-\mathrm{Cd}}=1.2$ accounts well for the experimental data. These values of the coordination numbers satisfy the bond-consisting relationship.

The obtained results confirm that amorphous $\mathrm{Cd}_{59} \Lambda \mathrm{s}_{41}$ and $\mathrm{Cd}_{26} \mathrm{As}_{74}$ are fourfold coordinated; in other words the investigated films consist of tetrahedral units within the estimated errors. The undercoordination of As in the As-rich film could be explained assuming the presence of threefold coordinated arsenic atoms.

\section{Summary}

The exact method for extracting the near neighbour structural information from the DAXS data has been developed. This technique, based on the curve-fitting procedure, has been applied to interpretation of the data for the amorphous Cd-As films containing 41 and 74 at.\% As. It has been found that the investigated films are tetrahedrally coordinated and chemically ordered.

\section{Acknowledgment}

This work is supported by the Committee for Scientific Research under Grant No. 2 P302 195 04. The Centre National de la Recherche Scientifique of France is gratefully acknowledged for a financial support under its reciprocal International Program for Scientific Cooperation (PICS).

\section{References}

[1] A.M. Flank, P. Lagarde, D. Udron, S. Fisson, A. Gheorghiu, M.L. Theye, J. Non-Cryst. Solids 07-08, 435 (1987).

[2] D. Udron, A.M. Flank, A. Glieorglin, P. Lagarde, M.L. Theye, Philos. Mag. Lett. 50, 9 (1989).

[3] D. Udron, M.L. Theye, D. Raoux, A.M. Flank, P. Lagarde, J. P. Gaspard, J. Non-Cryst. Solids 137-138, 131 (1991).

[1] D. Udron, A.M. Flank, P. Lagarde, D. Raoux, M.L. Theye, J. Non-Cryst. Solids 150, 361 (1992).

[5] S.H. Baker, M.I. Manssor, S.J. Gurman, S.C. Bayliss, E.A. Davis, J. Non-Cryst. Solids 144, 63 (1992).

[6] N. Elgun, S.J. Gyrman, E.A. Davis, J. Plyys., Condens. Maller 4, 7759 (1992). 
[7] S.C. Bayliss, S.H. Baker, J.S. Bates, S.J. Gurman, R. Bradley, E.A. Davis, J. Non-Cryst. Solids 164-166, 143 (1993).

[8] Q. Ma, D. Raoux, S. Benazeth, Phys. Rev. B 48, 16332 (1993).

[9] P.H. Fuoss, P. Eisenberger, W.K. Warburton, A. Bienenstock, Pliys. Rev. Lett. 46, 1537 (1981).

[10] A. Burian, P. Lecante, A. Mosset, J. Galy, Z. Kristallogr. 103, 199 (1990).

[11] S.N. Bagchi, Adv. Phys. 19, 119 (1970).

[12] S.N. Bagchi, Acta Crystallogr. A 28, 560 (1972).

[13] B.E. Warren, X-Ray Diffraction, Addison-Wesley, Massachusetts 1969.

[14] A. Burian, P. Lecante, A. Mosset, J. Galy, J.M. Tonnerre, D. Raoux, J. Non-Cryst. Solids 164-166, 151 (1993).

[15] H.P. Kunzi, H.G. Tzschach, C.A. Zehnder, Numerical Methods of Mathematical Optimization with Fortran Programs, Academic Press, New York 1971. 